\title{
Disbiose Intestinal em idosos e aplicabilidade dos probióticos e prebióticos
}

\author{
Intestinal dysbiosis in the elderly and applicability of probiotics and \\ prebiotics
}

\author{
1 Bruna Ágata Conrado bruna_conrado@hotmail.com \\ 1 Sinara Azevedo de Souza \\ 1 Aline Cristina Teixeira Mallet \\ 1 Elton Bicalho de Souza \\ 1 Alden dos Santos Neves \\ 1 Margareth Lopes Galvão Saron
}

1 UniFOA - Centro Universitário de Volta Redonda

\begin{abstract}
Intestinal dysbiosis can cause proliferation of pathogenic bacteria and consequent formation of metabolic toxins that can induce to inflammatory process. Thus, the aim of the present study has been a literature review about intestinal dysbiosis in the elderly as well as the applicability of probiotics and prebiotics. Therefore, it was performed a bibliographic review in the year 2016, using the search systems LILACS, BIREME, SciELO, PubMed, Digital library of thesis and dissertations, and technical books. Dysbiosis is considered an undesirable alteration of the intestinal microbiota that lead to an imbalance between protective and pathogenic bacteria. Probiotics and prebiotics, present in the feeding, act to keep the composition of the intestinal microbiota, generating benefic affects. Thus, it is important know the scientific evidences on intestinal dysbiosis in the elderly since the age factor itself can be a trigger for dysbiosis process. The elderly intestine undergoes physiological changes along the years and when combined with inadequate food habits, stress, use of antibiotics, among others factors, this intestine can become more vulnerable to the dysbiosis arising. Probiotics and prebiotics can help in treatment of dysbiosis, contributing to a healthier intestinal microbiota.
\end{abstract}

\section{Keywords}

Dysbiosis. Elder. Intestinal Microbiota. Probiotics. Prebiotics.

Disbiose. Idoso. Microbiota intestinal. Probióticos. Prebióticos.

\section{Como você deve citar?}

CONRADO, Bruna Ágata et al. Disbiose Intestinal em idosos e aplicabilidade dos probióticos e prebióticos. Cadernos UniFOA, Volta Redonda, n. 36, p. 71-78, abr. 2018. 


\section{INTRODUÇÃO}

O envelhecimento da população é uma realidade mundial que vem ocorrendo em um ritmo muito acentuado e sem precedentes na história da humanidade (CORRAL, 2010). A estimativa é que esse número alcance 1 bilhão em menos de dez anos e que duplique até 2050, alcançando, então, 2 bilhões de pessoas idosas, ou seja, $22 \%$ da população global (LISBOA; CHIANCA, 2012). Estima-se que a população mundial de idosos aumentará mais $300 \%$ nos próximos 50 anos, chegando a quase 2 bilhões, em 2050. No Brasil, as projeções mostram que, no ano de 2025, terá 32 milhões de pessoas idosas, colocando o país na sétima posição mundial em contingente de idosos (IBGE, 2000).

O envelhecimento é definido como um processo progressivo, no qual ocorrem alterações biológicas, funcionais, psicológicas que, com o passar do tempo, tendem a promover o declínio das funções (TEIXEIRA, 2010; MAHAN; STUMP, 2011). Por conta dessas mudanças progressivas no organismo, todos os sistemas sofrem alterações, assim como o aparelho digestório, que desenvolve alterações estruturais, de motilidade e da função secretora, que variam em intensidade e natureza, em cada segmento do aparelho (DIAS et al., 2000).

No intestino, ocorre a redução da superfície da mucosa e das vilosidades, alterações na motilidade, permitindo uma hiperproliferação de bactérias. Com essas alterações, poderá ocorrer um meio propício para o aparecimento de doenças do trato gastrintestinal, como a disbiose intestinal (CAVALLI et al., 2011).

Uma alteração indesejável da microbiota resulta em um desequilíbrio entre as bactérias protetoras e patogênicas, e esse desequilíbrio é denominado de disbiose (CHAN et al., 2013). Segundo Hawrelak et al. (2004), a disbiose é um estado no qual a microbiota produz efeitos nocivos, promovendo mudanças qualitativas e quantitativas na microbiota intestinal em si, em suas atividades metabólicas e em sua distribuição local.

As possíveis causas da disbiose são a má alimentação, a idade avançada, o estresse, a disponibilidade de material fermentável, a má digestão, o tempo de trânsito intestinal, o pH intestinal e o estado imunológico do hospedeiro. Outros fatores que podem ser atribuídos às causas do aparecimento dessa doença são: o uso indiscriminado de antibióticos, de anti-inflamatórios hormonais e não hormonais; o abuso de laxantes; o consumo excessivo de alimentos industrializados; a excessiva exposição às toxinas ambientais; as doenças, como câncer e síndrome da imunodeficiência adquirida (AIDS); as disfunções hepatopancreáticas; o estresse; a diverticulose e a hipocloridria, comum em pessoas idosas, associada a não destruição das bactérias patogênicas pela acidez estomacal (ALMEIDA et al., 2009).

Surge, então, a necessidade de uma nova ótica em nutrição, com a utilização dos alimentos não apenas para saciar a fome e fornecer energia ao corpo, mas também como forma de prevenção ao desenvolvimento de patologias. Nesse contexto, entram em cena os chamados alimentos funcionais, com destaque ao prébioticos, probióticos e simbióticos. A nutrição funcional é uma alternativa para tratamento, prevenção e controle da disbiose intestinal por usar a importância da funcionalidade do trato gastrintestinal como princípio básico, seguido pela especificidade bioquímica, terapêutica voltada ao paciente e não à patologia, estabilidade nutricional, biodisponibilidade de nutrientes e a intervenção de fatores externos à saúde orgânica (ALMEIDA et al., 2009; GAVANSKI, 2015).

É importante conhecer as evidências científicas sobre a disbiose intestinal no envelhecimento, visto que o próprio fator idade poderá ser um desencadeador do processo de disbiose, enquanto que a alimentação adequada e saudável poderá ser um fator protetor. Mediante ao exposto, este artigo teve como objetivo revisar, na literatura, as publicações a respeito da disbiose intestinal em idosos e a aplicabilidade dos probióticos e prebióticos. 
Bruna Ágata Conrado / Sinara Azevedo de Souza / Aline Cristina Teixeira Mallet Elton Bicalho de Souza I Alden dos Santos Neves I Margareth Lopes Galvão Saron

\section{MÉTODOS}

O presente artigo consistiu em uma pesquisa do tipo revisão bibliográfica realizada no ano de 2016, por meio de artigos indexados com as palavras-chave ou descritores em saúde: disbiose, idoso, microbiota intestinal, probióticos e prebióticos. Para realizá-la, foi feita uma busca eletrônica em diferentes bases de dados, sendo incluídas somente aquelas que apresentaram artigos referentes à temática proposta. As bases de dados consultadas foram LILACS (Literatura Latino-Americana em Ciências da Saúde e do Caribe), BIREME, SciELO e PubMed, Biblioteca Digital de Teses e Dissertações e livros técnicos publicados em inglês, espanhol e português.

\section{REVISÃO BIBLIOGRÁFICA}

As alterações fisiológicas ligadas ao envelhecimento não são as únicas responsáveis pelo declínio das funções orgânicas. Alguns fatores concomitantes ao processo de envelhecimento podem causar uma interferência na funcionalidade do organismo, inclusive no trato gastrintestinal, como dieta habitual, meio ambiente, atividade física, composição corporal, patologias, medicamentos, tabagismo e o estresse (NESELLO, 2011).

No intestino delgado, com o processo de envelhecimento, ocorre o enfraquecimento muscular e, consequentemente, alterações na peristalse, nos plexos nervosos e na musculatura do esfíncter exterior. No reto e ânus, são observadas alterações no espessamento da mucosa e alterações dos níveis de colágeno, o que encurta a força muscular e limita a capacidade de retenção fecal volumosa (FERRIOLLI et al., 2006).

O trato gastrintestinal humano é colonizado por microrganismos que, em sua maioria, são bactérias, mas também vírus, abrigando dez vezes mais bactérias que o número de células que formam nosso organismo. A composição bacteriana é diferente de cada pessoa, na qual partes são definidas geneticamente e outras por características individuais e ambientais, como o modo do nascimento, sendo parto normal ou cesariana, idade e hábitos alimentares, que contribuem para essa variedade da microbiota intestinal (MORAES et al., 2014).

Em condições homeostáticas, a microbiota intestinal exerce um papel central em numerosos aspectos benéficos. No entanto, em situações, como na presença de diarreias agudas, no tratamento antimicrobiano ou nas intervenções dietéticas restritivas, pode ocorrer um desequilíbrio e o crescimento excessivo das espécies patogênicas, tais como o Clostridium difficile (BÚRIGO et al., 2007). Os distúrbios no ecossistema intestinal são geralmente caracterizados pelo aumento de Enterobactérias e Streptococcus no intestino delgado (SARON et al., 2005).

Já no envelhecimento, podem ocorrer redução das colônias de bacteroides, bifidobacteria e menor produção de ácidos graxos de cadeia curta e, também, o crescimento de anaeróbios facultativos, como fusobactérias, clostrídeos, eubactérias e maior atividade proteolítica. Essas variações podem estar relacionadas à dieta, pois os alimentos ingeridos pelos indivíduos servirão de combustíveis às bactérias intestinais. Assim, uma dieta e hábitos alimentares inadequados poderão contribuir para o aparecimento da disbiose (MORAES et al., 2014).

Quando ocorre um desequilíbrio na microbiota intestinal normal, por meio de doenças ou da má alimentação, as condições de competição desaparecem e modifica-se o ambiente, criando um meio que propicia a proliferação de microrganismos transitórios e outros patogênicos sobreviventes. Esse desequilíbrio da microbiota intestinal é chamado de disbiose, uma condição de competição bacteriana, ocorrendo um aumento das bactérias patogênicas e a diminuição das benéficas (SANTOS; VARAVALLO, 2011). 
A disbiose é um problema grave, por isso deve ser muito bem investigada e tratada (ALMEIDA et al., 2009). Muitos fatores afetam a composição da microbiota intestinal, entre eles, a idade do individuo, requerimento nutricional e estado imunológico, pH estomacal, estresse, uso de antibióticos, drogas imunossupressoras, anti-inflamatórios, pílulas anticoncepcionais, laxantes, tempo de trânsito intestinal, interações entre os componentes da microbiota intestinal e presença de material fermentável no intestino (SARON et al., 2005; FAGUNDES, 2010).

Diante do quadro de disbiose, a mucosa do trato gastrintestinal não desempenhará com eficiência uma barreira, que excluirá numerosos antígenos derivados dos microrganismos e dos alimentos (HANSON et al., 1999).

As consequências advindas da disbiose estão associadas com diversas patologias, como, por exemplo, o câncer. Segundo Fagundes (2010), bactérias intestinais patogênicas produzem carcionógenos poderosos, como agente alquilantes e compostos nitrosos. Além disso, metabólitos bacterianos podem possuir atividade genotóxica, mutagênica ou carcinogênica e contribuir para o desenvolvimento de câncer, em um longo período de exposição. É interessante destacar que esse longo período de exposição é justamente o que ocorre na disbiose intestinal, uma vez que, na maioria dos casos, esse processo se inicia nos primeiros meses ou anos de vida e o câncer surge 30 ou 60 anos depois.

O diagnóstico da disbiose pode ser feito pela história de constipação crônica, flatulência e distensão abdominal; sintomas associados como fadiga, depressão ou mudanças de humor, culturas bacterianas fecais; e pelo exame clínico que revela abdome hipertimpânico e dor à palpação, particularmente do cólon descendente (ALMEIDA et al., 2009).

A constipação intestinal é também um dos fatores que ajudam no desenvolvimento da disbiose intestinal, pois altera a microbiota saudável do intestino, ocorrendo competição, onde as bactérias patogênicas ganham e, com isso, produzem toxinas que afetam a saúde do indivíduo (FAGUNDES, 2010). Na população idosa, a constipação constitui um problema sanitário importante, se tornando responsável por cerca de 2,5 milhões de visitas médicas, e, indiretamente, por 92 mil hospitalizações, nos Estados Unidos, a cada ano e, no Brasil, a prevalência de constipação intestinal encontrada no estudo de Klaus e col. (2015) foi de $42,5 \%$.

A ingestão de probióticos, prebióticos e simbióticos são muito importantes, pois as bifidobactérias produzem sais orgânicos que estimulam o peristaltismo, acelerando o trânsito intestinal e, por consequência, melhorando a constipação intestinal. 0 consumo de alimentos probióticos promove a diminuição da quantidade de substâncias putrefativas presentes nas fezes (tais como amônia) e melhora a constipação intestinal pelo aumento de volume da massa fecal (ANTUNES et al., 2007).

Os probióticos, prebióticos e simbióticos, que podem ser encontrados em alimentos presentes na alimentação habitual do brasileiro, atuam na manutenção da composição da microbiota intestinal, produzindo efeitos benéficos. O balanço dessa composição é importante para a saúde do hospedeiro (STEFE et al., 2008). Os probióticos são microrganismos vivos que, administrados em quantidades adequadas, proporcionam benefícios à saúde humana (SANTOS; VARAVALLO, 2011).

A influência benéfica dos probióticos sobre a microbiota intestinal humana inclui fatores como competição e efeitos imunológicos promovendo o aumento da resistência contra patógenos. Dessa forma, a utilização de prebióticos estimula a multiplicação de bactérias benéficas que, por consequência, diminui a proliferação de bactérias patogênicas, aumentando os mecanismos naturais de defesa do organismo (SAAD, 2006). 
Bruna Ágata Conrado / Sinara Azevedo de Souza / Aline Cristina Teixeira Mallet Elton Bicalho de Souza I Alden dos Santos Neves I Margareth Lopes Galvão Saron

Como benefícios dos probióticos, podem ser citados a modulação da microbiota intestinal, reestruturação da microbiota intestinal após o uso de antibióticos, promoção de resistência gastrintestinal e urogenital à colonização por microrganismos patogênicos, alívio da constipação intestinal, tratamento de alguns tipos de diarreias e produção de algumas vitaminas (SANTOS; VARAVALLO, 2011).

Os probióticos também são importantes na regulação do sistema imune, principalmente pelo controle do balanço das citocinas pró e anti-inflamatórias, melhora das respostas imunoglobulina A (IgA) e componentes celulares das bifidobactérias que agem como imunomoduladores. Trabalhos experimentais confirmam essa capacidade imunoestimuladora que significa o aumento de anticorpos, da atividade de macrófagos, do número de células killer, do número de células T e de interferon (STEFE et al., 2008).

O uso de antibióticos, uma prática comum entre os idosos, traz consequentemente o aumento de infecções, pois esses antibióticos alteram a função dos macrófagos. Essa alteração é reconstituída pelo aporte de peptídeos de baixo peso molecular, obtidos da microbiota intestinal. Alguns estudos têm demonstrado que o suplemento com probióticos reconstitui os componentes da parede bacteriana, com o peptídeoglicano, estimulando a função dos macrófagos (STEFE et al., 2008).

Já os prebióticos, são componentes alimentares que não são digeridos pelo organismo. São importantes, pois estimulam a proliferação ou atividade das bactérias benéficas para o organismo no cólon, e podem inibir o crescimento de bactérias patogênicas, garantindo benefícios à saúde do hospedeiro. Os prebióticos têm a sua atuação principal no intestino grosso, mas também podem ter algum impacto na microbiota do intestino delgado (SAAD, 2006).

Os oligossacarídeos, que contêm frutose, como a oligofrutose e a inulina, têm o potencial de estimular as bifidobactérias do cólon. Há várias pesquisas em humanos que confirmam os benefícios à saúde da ingestão de inulina, promovendo a melhora das funções intestinais e da microbiota colônica e ainda o aumento na absorção de minerais. Os estudos científicos evidenciam um aumento significativo no número de bifidobactérias, após ingestão de inulina e/ou oligofrutoses. Além disso, as contagens permaneceram estáveis, mediante a ingestão contínua do prebiótico e diminuíram progressivamente, quando retirada a administração, sugerindo que o efeito benéfico associou-se ao uso contínuo dos prebióticos (PIMENTEL et al., 2012).

As ingestões diárias desses prebióticos podem resultar em um aumento de bifidobactérias, e a adesão dessas bactérias ao trato gastrintestinal, mudando a composição de sua microbiota. Ao mesmo tempo, acabam sendo inibidores de crescimento de bactérias patogênicas, como Escherichia coli, Clostridium perfringens, entre outras (PASSOS; PARK, 2003; SAAD, 2006).

Os simbióticos são produtos nos quais os probióticos e os prebióticos estão combinados. A interação entre o probiótico e o prebiótico in vivo pode ser favorecida por uma adaptação do probiótico ao substrato prebiótico anterior ao consumo, podendo melhorar enormemente a eficácia das bactérias viáveis e resultando em uma vantagem competitiva para o probiótico, se ele for consumido juntamente com o prebiótico (SAAD, 2006).

A combinação existente nos simbióticos deve possibilitar a sobrevivência da bactéria probiótica no alimento e nas condições do meio gástrico, possibilitando sua ação no intestino grosso (STEFE et al., 2008).

Para que os probióticos exerçam seus efeitos, se faz necessário uma ingestão diária. 0 produto alimentício precisa conter $10^{6}$ a $10^{9}$ (UFC). Os prebióticos precisam de doses diárias a partir de 4 a $5 \mathrm{~g}$, chegando até $20 \mathrm{~g}$, sendo inulina, oligofrutose e/ou FOS, que, quando administradas durante pelo menos 15 dias, são eficientes para garantir o estímulo da multiplicação de bifidobactérias no cólon (KOMATSU et al., 2008). 
As culturas probióticos, prebióticos e simbióticos são chaves para restabelecer a microbiota intestinal, quando ocorre a disbiose (SANTOS; VARAVALLO, 2011).

A possibilidade de manipular a microbiota intestinal por introdução na dieta dos prebióticos e/ ou probióticos permite potencializar essas capacidades benéficas, contribuindo com uma microbiota intestinal mais saudável (SARON et al., 2005).

0 tratamento da disbiose consiste na abordagem dietética, por meio da ingestão de alimentos que contenham probióticos e/ou prebióticos. Nos casos mais críticos, pode haver a necessidade de lavagens colônicas (hidrocolonterapia), para remover conteúdos putrefativos do intestino e permitir a drenagem linfática do cólon, o tratamento nutricional por sua vez, tem início com a inserção de alimentos que contenham probióticos e/ou prebióticos associados ao uso ou não de simbióticos, podendo contribuir para melhora no quadro geral do paciente (ALMEIDA et al., 2009).

Sendo assim, as campanhas de educação nutricional tornam-se importantes para promover a saúde por meio de melhores práticas alimentares e do autocuidado dos indivíduos, já que uns dos principais problemas de saúde nos idosos estão relacionados diretamente com a alimentação e o estilo de vida (WACHHOLZ et al., 2012). As evidências atuais revelam que os fatores dietéticos afetam o ecossistema microbiano no intestino (CHAN et al., 2013).

\section{CONSIDERAÇÕES FINAIS}

O intestino do idoso sofre alterações fisiológicas ao longo dos anos e, quando aliado aos hábitos alimentares inadequados, ao estresse, ao uso de antibióticos, entre outros fatores, esse órgão poderá se tornar mais vulnerável ao aparecimento da disbiose.

A disbiose intestinal tem tratamento, que consiste em uma reeducação alimentar e suplementação com o uso diário de probióticos e/ou prebióticos e/ou simbióticos, que terão um papel importante na composição da microbiota intestinal, diminuindo e até eliminando os sintomas do desequilíbrio das bactérias intestinais.

É possível prevenir a disbiose intestinal na terceira idade, com hábitos de vida saudáveis, como a prática de atividade física, alimentação adequada e com a ingestão alimentar diária de probióticos, prebióticos e simbióticos. 
Bruna Ágata Conrado / Sinara Azevedo de Souza / Aline Cristina Teixeira Mallet Elton Bicalho de Souza I Alden dos Santos Neves I Margareth Lopes Galvão Saron

\section{REFERÊNCIA}

ALMEIDA, L. B.; MARINHO, C. B.; SOUZA, C. S.; CHEIB, V. B. P. Disbiose intestinal. Revista Brasileira de Nutrição Clínica. v. 24, n. 1, p. 58-65. 2009.

ANTUNES, A. E. C.; SILVA, E. R. A.; MARASCA, E. T. G.; MORENO, I.; LERAYER, A. L. S. Probióticos: agentes promotores de saúde. Nutrire: Revista da Sociedade Brasileira de Alimentação e Nutrição. v. 32, n. 3, p. 103-122. 2007.

BÚRIGO, T.; FAGUNDES, R. L. M.; TRINDADE, E. B. S. M.; VASCONCELOS, H. C. F. F. Efeito bifidogênico do frutooligossacarídeo na microbiota intestinal de pacientes com neoplasia hematológica. Revista de Nutrição. v. 20, n. 5, p. 491-497. 2007.

CAVALLI, L. F; FREIBERGER, C; KRAUSE, K. M. O.; NUNES, M. Principais Alterações Fisiológicas que Acontecem nos Idosos: uma Revisão Bibliográfica. Seminário Interinstitucional de Ensino, Pesquisa e Extensão, n. 16, 2011. Universidade de Cruz Alta/UNICRUZ. [Apostila]. Disponível em: <http://www. unicruz.edu.br/seminario/anaisArtigos.php\#inicio>. Acesso em: 10 set. 2016.

CHAN, Y. K.; ESTAKI, M.; GIBSON, D.L. Clinical Consequences of Diet-Induced Dysbiosis. Ann. Nutr. Metab.; v. 63, suppl. 2, p. 28-40, 2013.

CORRAL, L.R. Epidemiologia da terceira idade no brasil. In: MAGNONI, D.; CUKIER, C.; OLIVEIRA, P.A. Nutrição na terceira idade. 2 ed. São Paulo: Sarvier, 2010. P. 3-13, 2010.

DIAS, A. A. C. et al. Constipação no idoso: mitos e verdades. Rev. Cient. AMECS, v. 9, n. 1, p.35-39, 2000.

FAGUNDES, G. E. Prevalência de sinais e sintomas de disbiose intestinal em estudantes do curso de nutrição da universidade do extremo sul catarinense. Universidade do Extremo Sul Catarinense, UNESC, 2010. p. 43. Monografia (TCC).

FERRIOLLI, E; MORIGUTI, J.C.; LIMA, N. K. C. Envelhecimento do Aparelho Digestório. In: FREITAS, E. V; CANÇADO, F. A. X; DOLL, J.; GORZONI, M. L. Tratamento de Geriatria e Gerontologia. Rio de Janeiro: Editora Guanabara Koogan S. A., 2006. p. 638 - 639.

GAVANSKI, D. S.; BARATTO, I.; GATTI, R. S. Avaliação do hábito intestinal e ingestão de fibras alimentares em uma população de idosos. Revista brasileira de obesidade, nutrição e emagrecimento, São Paulo. v.9. n.49. p.3-11, 2015.

HANSON, L.A.; et al. Normal Microbial Flora of the gut and the immune system. In: HANSON, L.A.; YOLKEN, R.H. Probiotics, other nutrition factors, and intestinal microflora. Nestlé Nutrition Workshop Series 42, Lippincott-Raven. Philadelphia. 1999.

HAWRELAK, J. A; MYERS, S. P. The Causes of Intestinal Dysbiosis: A Review. Alternative Medicine Review, v. 9, n. 2, p. 180-197, 2004.

IBGE. Instituto Brasileiro de Geografia e Estatística. Censo Demográfico 2000. Brasília. Disponível em: $<$ http://www.ibge.gov.br>. Acesso em: 10 set. de 2016. 
KLAUS, J. H.; DE NARDIN, V.; PALUDO, J.; SCHERER, F.; DAL BOSCO, S. M. Prevalência e fatores associados à constipação intestinal em idosos residentes em instituições de longa permanência. Rev. Bras. Geriatr. Gerontol., Rio de Janeiro, v.18, n. 4, p. 835-843, 2015.

KLAUS, J.H.; NARDIN, V.; PALUDO, J.; et al. Prevalência e fatores associados à constipação intestinal em idosos residentes em instituições de longa permanência. Rev. Bras. Geriatr. Gerontol., Rio de Janeiro, v.18, n.4, p. 835-843, 2015.

KOMATSU, T. R; BURITI, F. C. A.; SAAD, S. M. I. Inovação, persistência e criatividade superando barreiras no desenvolvimento de alimentos probióticos. Revista Brasileira de Ciências Farmacêuticas, v. 44, n. 3, p. 329-347, 2008.

LISBOA, C. R.; CHIANCA, T.C.M. Perfi I epidemiológico, clínico e de independência funcional de uma população idosa institucionalizada. Rev Bras Enferm, v. 65, n. 3, p.482-7, 2012.

MAHAN, K .L.; STUMP, E. S. Krause: alimentos, nutrição e dietoterapia. In: PETER L; BEYER M. S. Tratamento Médico Nutricional para Doenças do Trato Gastrointestinal Inferior. $12^{\circ}$ ed. Rio de Janeiro: Editora Elsevier, 2011. p. 696.

MORAES, A. C. F; SILVA, I. T; PITITTO, B. A; FERREIRA, S. R. G. Microbiota intestinal e risco cardiometabólico: mecanismos e modulação dietética. Arq. Bras. Endocrinol. Metab; v. 58, n. 4, p. 317 - 327, 2014.

NESELLO, L. A. N.; TONELLI, F. O.; BELTRAME, T. B. Constipação intestinal em idosos frequentadores de um Centro de Convivência no município de Itajaí-SC. Ceres: Nutrição e Saúde; v. 6, n. 3, p. 151-162, 2011.

PASSOS, L. M. L.; PARK, Y. K. Frutooligossacarídeos: implicações na saúde humana e utilização em alimentos. Ciência Rural, v. 33, n. 2, p. 385-390, 2003.

PIMENTEL, T. C.; GARCIA, S.; PRUDENCIO, S. H. Aspectos funcionais, de saúde e tecnológicos de frutanos tipo inulina. B.CEPPA, v. 30, n. 1, p.103-118. 2012.

SAAD, S. M. I. Probióticos e prebióticos: o estado da arte. Revista Brasileira de Ciências Farmacêuticas, v. 42 , n. 1, p. 1-16, 2006.

SANTOS, T. T; VARAVALLO, M. A. A. importância de probióticos para o controle e/ou reestruturação da microbiota intestinal. Revista Científica do ITPAC, v. 4, n. 1. P. 40-49, 2011.

SARON, M.L.G.; SGARBIERI, V.C.; LERAYER, A.L.S. Prebióticos: efeitos benéficos à saúde humana. Nutrire: Rev. Soc. Bras. Alim. Nutr., v. 30, p. 117-130, dez. 2005.

STEFE, C. de A.; ALVES, M. I. R.; RIBEIRO, R. L. Probióticos, prebióticos e simbióticos - artigo de revisão. Saúde \& Ambiente em Revista, Duque de Caxias, v.3, n.1, p.16-33, 2008.

TEIXEIRA, R. Nutrição: um guia completo de alimentação, práticas de higiene, cardápios, doenças, dietas e gestão. $1^{\circ}$ ed. São Paulo: Editora Rideel, 2010. 